Archives de sciences sociales des religions

115 | juillet-septembre 2001

Islam et politique dans le monde (ex-)communiste

\title{
Trois définitions de l'islam en Bosnie-Herzégovine
}

\section{Xavier Bougarel}

\section{OpenEdition}

Journals

Édition électronique

URL : http://journals.openedition.org/assr/18673

DOI : $10.4000 /$ assr. 18673

ISSN : $1777-5825$

Éditeur

Éditions de l'EHESS

Édition imprimée

Date de publication : 1 octobre 2001

Pagination : 183-201

ISBN : 2-222-96707-4

ISSN : 0335-5985

Référence électronique

Xavier Bougarel, «Trois définitions de l'islam en Bosnie-Herzégovine ", Archives de sciences sociales des religions [En ligne], 115 | juillet-septembre 2001, mis en ligne le 19 août 2009, consulté le 10

décembre 2020. URL : http://journals.openedition.org/assr/18673; DOI : https://doi.org/10.4000/assr 18673

Ce document a été généré automatiquement le 10 décembre 2020.

() Archives de sciences sociales des religions 


\title{
Trois définitions de l'islam en Bosnie-Herzégovine
}

\author{
Xavier Bougarel
}

\section{La diversité de l'islam bosniaque : enjeux réels et faux- semblants}

1 À partir de 1878, date à laquelle la Bosnie-Herzégovine est sortie de l'Empire ottoman, les Musulmans bosniaques n'ont cessé de débattre et de se débattre autour de leur identité musulmane. Ce retour sur soi a souvent pris la forme d'enjeux symboliques, comme l'illustrent les vives polémiques de l'entre-deux-guerres sur le port du voile et du fez, ou les interrogations lancinantes des années 1970 sur la nature des liens existant entre le nom religieux «musulman» (« $\mathrm{m}$ » minuscule) et le nom national «Musulman » (« $\mathrm{M}$ » majuscule), nouvellement promu par la Ligue des Communistes de Bosnie-Herzégovine. De même, ces interrogations ont été alimentées par diverses influences extérieures, telles que le réformisme salafite de Jamaluddin Afghani et Muhammad Abduh à partir de la fin du XIX ${ }^{e}$ siècle, le revivalisme islamique de Rashid Rida et le panislamisme de Shakib Arslan dans les années 1930, ou encore le « socialisme islamique » de Muhammad Iqbal et l'islamisme radical de Sayyid Qutb dans les années 1960 et 1970.

2 Au-delà de ces enjeux et de ces apports conjoncturels, le débat sur l'islam en BosnieHerzégovine s'est durablement structuré autour de trois questions qui, sans être propres à cette région du monde, y prennent des formes spécifiques. Ces questions concernent : 1) les rapports entre islam et identité nationale des Musulmans bosniaques 2) les rapports entre islam et système politique en Bosnie-Herzégovine 3) la place de la BosnieHerzégovine dans les rapports entre monde musulman et monde occidental. L'éclatement de la fédération yougoslave et l'indépendance de la Bosnie-Herzégovine au début des années 1990, immédiatement suivies par trois ans de guerre fratricide (avril 1992décembre 1995), ont profondément modifié le contexte dans lequel ces trois questions se situent. Mais, les Musulmans bosniaques disposant désormais d'une souveraineté 
politique propre, et s'étant trouvés propulsés au centre de l'attention du monde musulman ${ }^{1}$, elles apparaissent plus actuelles que jamais.

Malheureusement, le contexte de la guerre et de l'après-guerre n'en ont pas permis une formulation explicite et sereine. Jusqu'en décembre 1995, l'islam est resté un sujet largement tabou au sein de la communauté musulmane ${ }^{2}$. Alors que les propagandes serbe et croate qualifiaient tous les Musulmans bosniaques de «fondamentalistes» et de "moudjahidin" en puissance, ceux-ci plaçaient leurs espoirs dans une intervention extérieure, et s'efforçaient dès lors d'apparaître comme les défenseurs unanimes de la démocratie et $\mathrm{du}$ multiculturalisme. L'après-guerre, au contraire, a favorisé un déchaînement de griefs et de désaccords restés jusque-là sous-jacents, et l'islam est devenu un des principaux sujets de polémique dans les médias et les conversations courantes. Mais la vigueur de ces débats dissimule mal leur faible articulation, slogans et anathèmes se substituant souvent aux arguments de fond.

4 En fait, dans les territoires sous contrôle musulman, le pouvoir a vite été monopolisé par le Parti de l'action démocratique (SDA), parti nationaliste musulman créé en 1990 à l'initiative des représentants d'un courant panislamiste apparu dans les années 1930 et reconstitué dans les années $1970^{3}$. Mais les tentatives de réislamisation autoritaire conduites par le SDA et son noyau fondateur se sont heurtées aux résistances multiformes d'une population largement sécularisée. Inhabituelle et la plupart du temps implicite, cette configuration interne à la communauté musulmane a échappé aux observateurs extérieurs, ou a été réduite à une conséquence logique de la guerre. À partir de 1996, le passage de la Bosnie-Herzégovine sous tutelle internationale a en outre limité la marge de manœuvre des dirigeants du SDA, suggérant cette fois un «retour à la normale » tout aussi inévitable et spontané. Dans un cas comme dans l'autre, la diversité interne de l'islam, les enjeux autour desquels elle s'articule, les acteurs qui la constituent et qui l'animent ont donc été largement ignorés.

5 À défaut de pouvoir décrire cette diversité dans toute sa complexité et toutes ses manifestations concrètes, nous tenterons d'en restituer les principaux enjeux en nous appuyant sur quelques figures emblématiques de l'islam bosniaque contemporain. Les trois intellectuels (religieux ou laïcs) retenus ici l'ont été pour plusieurs raisons. D'abord, au-delà des mandats politiques ou religieux qu'ils ont exercés, ces intellectuels sont surtout connus pour leurs écrits. Ensuite, dans leurs prises de position individuelles, ils ont abordé les trois questions centrales dégagées précédemment. Enfin, dans ce cadre, chacun d'entre eux incarne une des définitions de l'islam à partir desquelles s'organise la diversité de la communauté musulmane bosniaque, à savoir l'islam défini comme foi individuelle, comme culture commune ou comme idéologie politique discriminante.

\section{Fikret Karčić : l'islam comme foi individuelle}

Le premier des intellectuels retenus est Fikret Karčić. Né à Višegrad (Bosnie orientale) en 1955, il suit des études secondaires à la madrasa de Sarajevo, dont il obtient le diplôme en 1973. Par la suite, il entreprend des études de droit, soutient un mémoire sur «Les tribunaux chariatiques en Yougoslavie 1918-1941 » en 1985, puis une thèse de doctorat sur « Le mouvement pour la réforme du droit chariatique et son influence en Yougoslavie dans la première moitié $d u X X^{e}$ siècle » en $1989^{4}$. Spécialiste du fikh (science du droit chariatique), il enseigne à partir de 1978 à la Faculté de théologie islamique de Sarajevo. À la fin des années 1980, il est élu président du Sabor (Assemblée) de l'Islamska Zajednica (Communauté islamique) 
pour la Bosnie-Herzégovine, et commence ainsi à exercer des responsabilités religieuses importantes. En 1989, suite à une grave crise interne des institutions religieuses islamiques, il participe à la rédaction d'une nouvelle Constitution pour l'Islamska Zajednica de Yougoslavie, et devient un des proches conseillers du nouveau Reis-ul-Ulema Jakub Selimoski. Enfin, quelque temps après l'éclatement du conflit bosniaque, il quitte la Bosnie-Herzégovine pour la Malaisie et devient professeur associé à l'Université islamique internationale de Kuala Lumpur.

7 C'est d'abord à travers son rôle de conseiller juridique que F. Karčić est amené à développer sa propre conception de l'islam. Outre qu'il participe à la rédaction de la nouvelle Constitution de l'Islamska Zajednica, F. Karcić est en effet chargé de définir l'attitude de cette dernière face à l'introduction du multipartisme. Dans un texte publié en janvier 1990, il écrit à ce sujet que « les communautés religieuses et leurs fidèles ne sont pas seulement un objet de la démocratisation, mais aussi des participants actifs à ce processus », car «les membres de chaque communauté religieuse (...) représentent une partie importante du corps électoral, dont l'engagement politique est une condition nécessaire à l'édification d'une société démocratique ». Dans ce contexte, il estime « indispensable que les communautés religieuses définissent les "règles du jeu" valables pour les institutions et les fonctionnaires religieux ».

8 F. Karčić considère en particulier que l'Islamska Zajednica, tout en soutenant le processus de démocratisation et en demandant le rétablissement de certaines libertés religieuses, doit affirmer sa neutralité politique. Pour lui, l'introduction du multipartisme est même l'occasion d'en finir avec l'instrumentalisation politique des institutions religieuses: «Dans un système moniste, si quelqu'un ne voulait pas ou ne pouvait pas agir dans le cadre du parti au pouvoir, il le faisait au sein d'une des institutions existantes. Parfois, il pouvait s'agir de la communauté religieuse. Dans un système doté de plusieurs partis politiques, cela est exclu ». F. Karčić souhaite donc interdire aux oulémas l'exercice de toute responsabilité politique, les choix partisans et électoraux restant « l'affaire de la conscience de chaque fidèle. Les fidèles se laisseront alors guider par le critère suivant: dans quelle mesure le programme d'un parti intègre les valeurs et les principes généraux de l'enseignement islamique ». Surtout, il se prononce résolument contre la création d'un parti musulman ou islamique :

9 «La règle de neutralité de l'I[slamska] Z[ajednica] doit s'appliquer particulièrement face à des partis "musulmans" ou, le cas échéant, "islamiques". L'histoire de la vie politique de la Yougoslavie d'avant-guerre ou de certains pays musulmans contemporains est pleine d'exemples de déplacement des luttes partisanes du terrain politique vers celui des institutions religieuses, de lutte entre partis "musulmans" pour influencer les institutions, les instances et les fondations islamiques. Une telle situation a systématiquement des conséquences négatives $»^{5}$.

10 Bien que reprises dans différentes résolutions des instances dirigeantes de l'Islamska Zajednica, les positions élaborées par F. Karčić ont du mal à se traduire dans les faits, comme l'attestent la création du SDA par les représentants du courant panislamiste, son instrumentalisation des symboles de l'islam à des fins nationalistes, et le soutien à peine dissimulé que lui apporte la plupart des oulémas ${ }^{6}$. Ces positions restent toutefois significatives, dans la mesure où y transparaissent les deux thèmes centraux qui animent la réflexion de F. Karčić, à savoir la séparation entre la religion et l'État et l'individualisation de la foi qui en découle. 
11 Dans ses travaux sur le droit chariatique, en effet, F. Karčić s'intéresse d'abord à son adaptation au monde moderne et à l'État séculier, et tente d'en dégager les modalités. Dès 1985, il note ainsi qu' «après l'abolition des tribunaux chariatiques d'État [en 1947], l'essence de certaines institutions et de certains principes de droit chariatique se perpétue sous la forme des principes et des usages religieux et moraux des citoyens yougoslaves de religion islamique $»^{7}$. Six ans plus tard, au cours d'un colloque sur le droit dans l'islam, il oppose les États musulmans, dans lesquels la chariat constitue un «droit territorial » applicable à tous, aux États possédant une minorité musulmane, et dans lesquels la chariat ne peut être qu'un "droit personnel », voire un simple " code moral personnel des musulmans pratiquants $»^{8}$. Enfin, en réponse aux accusations de la presse serbe, il estime que « l'État séculier (...) est le meilleur modèle d'organisation des rapports entre autorités politiques et religieuses pour les sociétés pluriconfessionnelles ", se déclare personnellement "réservé envers quelque État idéologique que ce soit ", et considère donc que "l'idée d'une "république islamique" en Bosnie-Herzégovine n'a aucun fondement théorique et pratique ${ }^{9}$.

12 Partant du cas bosniaque, F. Karčić étend ses analyses et ses prises de position au monde musulman et à l'islam en général. Dans sa thèse de doctorat, il écrit ainsi que « les fonctions sociales de tout droit, y compris du droit chariatique, dépendent de l'état des rapports sociaux dans les sociétés concrètes. La chariat comporte en soi des éléments qui peuvent avoir des conséquences sociales, économiques, culturelles et politiques variées. Les fonctions sociales de ce droit vont dépendre des éléments sur lesquels est mis l'accent. Le droit chariatique peut être au service de la modernisation sociale, de la démocratisation du système politique et juridique et de l'ouverture aux autres cultures, ou bien de processus rétrogrades qui peuvent avoir pour conséquences le dogmatisme, le conservatisme, le totalitarisme politique et l'autarcie culturelle ${ }^{10}$. Plus tard, dans sa typologie des interprétations juridiques contemporaines de l'islam, F. Karčić distingue quatre courants principaux :

13 - les sécularistes, pour qui « l'islam est une religion dans le sens communément admis du mot dont le champ d'expression légitime est la sphère personnelle, privée de l'individu. Ils soulignent les valeurs morales de l'islam mais ne considèrent plus son enseignement comme étant le fondement du système social, politique et juridique » ;

14 - les traditionalistes, pour qui « l'islam se définit comme "religion et droit", mais [qui acceptent] les modifications historiques de sa fonction sociale et du domaine de validité de la loi islamique. La différenciation historiquement constituée entre normes et institutions religieuses et séculières est acceptée, ainsi que la domination de fait des institutions séculières »;

15 - les modernistes islamiques, qui considèrent qu'« un enseignement islamique renouvelé peut représenter un fondement idéologique approprié pour la vie publique dans les pays musulmans, et que le droit chariatique reformulé peut devenir la base ou une composante importante du système de droit positif »;

16 - les revivalistes qui «s'efforcent tout particulièrement de construire une idéologie complète à partir des sources principales de l'enseignement islamique et de l'histoire musulmane précoce » et "donnent à l'expérience de la communauté musulmane originelle de Médine un caractère normatif, la considérant comme un modèle et non comme un exemple historique de réalisation de l'islam ${ }^{11}$. 
17 Finalement, la réflexion de F. Karčić sur l'interprétation et la modernisation de la chariat l'amènent à esquisser une justification islamique du principe de laïcité. Dans un texte intitulé « Signification et expression de l'islam dans l'État laïc », il considère en effet qu'avec la séparation de la religion et de l'Etat, « les communautés religieuses perdent de nombreux privilèges (...) mais, en même temps, deviennent libres de gérer leurs propres affaires sans ingérence de l'État » et « obtiennent la possibilité de se consacrer entièrement à leur mission première : la satisfaction des besoins religieux de leurs membres ». Selon lui, "dans un État laïc, chaque religion est traitée comme l'affaire privée des citoyens, est exclue de la politique et n'exerce aucune influence sur le droit. Tel est le statut qu'a et que doit avoir l'islam, conformément au principe d'égalité entre les religions.(...) l'islam ne peut être qu'une religion, et son domaine légitime d'expression est la vie privée des citoyens ». Dans ce contexte, précise-t-il, « certaines composantes du message de l'islam prennent une signification différente », et «les jugements de valeur exprimés dans les prescriptions concernant les mu'amelat [relations sociales] ne survivent que dans la mesure où elles sont transférées dans les coutumes ou dans la morale personnelle des individus $»^{12}$.

Dans ce texte qui résume bien sa démarche intellectuelle, F. Karčić tente également de rompre avec la représentation islamique classique du monde, en affirmant qu'« il serait théoriquement infondé, et historiquement anachronique d'appliquer aux relations internationales contemporaines les catégories de "maison de l'islam" [daral-islam] ou de "maison de la guerre" [dar al-harb ${ }^{13}$ ], ou de ranger la situation des musulmans vivant dans des pays à société laïque dans cette dernière catégorie ». C'est sur cette même question de la représentation du monde - et de l'islam bosniaque en son sein - que F. Karčić concentre son attention pendant la guerre.

À partir de 1992, en effet, F. Karčić semble interrompre sa réflexion sur le droit chariatique, sans toutefois la renier à aucun moment. Il s'attache par contre à présenter sous ses vraies formes - "principalement lié aux sphères religieuse et culturelle » - le renouveau de l'islam balkanique ${ }^{14}$, et à en dénoncer les présentations tendancieuses venues de Serbie ou des pays occidentaux ${ }^{15}$. Derrière ces préoccupations directement motivées par la guerre se profile aussi une préoccupation plus générale: à Samuel Huntington qui évoque un possible " clash des civilisations », F. Karčić rétorque que « s'il existe aujourd'hui en Bosnie-Herzégovine des éléments de guerre civile, de guerre de religion ou de conflit entre civilisations, ils sont créés délibérément pour dissimuler l'essentiel : l'agression, la conquête territoriale, le génocide ", et conclue ainsi sa réflexion sur les thèses du professeur de Harvard : « De toute évidence, certains cercles influents en Occident voient à l'œuvre en Bosnie-Herzégovine un conflit entre civilisations. Les Bochniaques [musulmans] qui acceptent une telle interprétation ou qui commenceraient à adopter un comportement conforme à celle-ci ne feraient que confirmer l'hypothèse. Cela semble paradoxal, mais le peuple qui est accusé de fondamentalisme se bat contre la différenciation des civilisations, se bat pour que les "lignes de discontinuité" deviennent les lignes d'une coexistence fructueuse, et non d'un affrontement inévitable. $»^{16}$ Malgré la guerre, le souci de F. Karčić de concilier islam et modernité occidentale et d'en privilégier les formes individuelles plutôt que collectives reste donc entier. 


\section{Enes Karić : l'islam comme culture commune}

21 Né en 1958 à Travnik (Bosnie centrale) au sein d'une famille d'imam, Enes Karić suit lui aussi les cours de la madrasa de Sarajevo, et participe en outre au cercle de discussion informel créé dans les années 1970 par Husein Djozo ${ }^{17}$.

Diplômé de la madrasa en 1978, il suit des études de journalisme et de philologie, et enseigne à partir de 1982 le tefsir (interprétation du Coran) à la Faculté de théologie islamique de Sarajevo. En 1989, il soutient une thèse de doctorat sur les «Problèmes herméneutiques de la traduction du Coran en langue serbo-croate $\aleph^{18}$. Vers la même époque, il joue un rôle moteur dans le renouveau intellectuel de l'Islamska Zajednica, animant la revue «Islamska Misao » (« La pensée islamique »), publiant deux ouvrages collectifs sur « Les interprétations idéologiques contemporaines du Coran et de l'islam» et "Le Coran dans la période contemporaine $»^{19}$, et popularisant les travaux de Seyd Hussein Nasr, Fazlur Rahman et Mohamed Arkoun. Ce rôle d'« électron libre » ne tarde pas à lui attirer les foudres de sa hiérarchie et, en mars 1991, il est destitué de la direction de «Islamska Misao » par Salih Čolaković, président de l'Islamska Zajednica de Bosnie-Herzégovine proche des réseaux wahhabites financés par l'Arabie Saoudite.

Par la suite, E. Karić poursuit ses activités religieuses, comme l'atteste la parution d'une traduction du Coran en langue bosniaque en $1995^{20}$. Mais c'est surtout par ses activités politiques qu'il se fait connaître. Collaborateur actif de "Muslimanski Glas» («La voix musulmane », organe officieux du SDA), il est élu en décembre 1992 vice-président du Conseil du Congrès des intellectuels musulmans, nouvellement créé à Sarajevo. En juin 1994, il est nommé ministre de l'Education et de la Culture par le Premier ministre Haris Silajdžić. Il soutient celui-ci dans ses désaccords grandissants avec les instances dirigeantes du SDA et, en janvier 1996, quitte son ministère pour participer à la création du Parti pour la Bosnie-Herzégovine lancé par H. Silajdžić. Après l'échec relatif de ce parti aux élections de septembre 1996, il met un terme à ses activités politiques et se consacre à la Fondation Ibn Sina (Avicenne), fondation philosophico-religieuse soutenue par l'Iran.

De même que le droit chariatique est à la base des réflexions de F. Karčić, le Coran nourrit celles de E. Karić. Dans sa thèse de doctorat, il insiste d'abord sur son caractère ouvert, polysémique et irrévocablement mystérieux, pour montrer ensuite comment la traduction du Coran en est toujours une interprétation, et justifier enfin la pluralité de ces interprétations, tant sur le plan historique ( du fait du caractère exceptionnellement ouvert de ce tissu, chaque époque a sa lecture, sa "vocalisation", et donc sa traduction du Coran», p. 218) que géographique: "Le destin de l'islam se situe dans les théologies qualifiées de "mineures" ou "régionales". Historiquement, les nombreux systèmes théologiques régionaux de l'islam ont joui et jouissent d'une large autonomie grâce justement à ces multiples interprétations et "visages" du Coran. Nous avons donc affaire à plusieurs lectures correctes du Coran, ce qui a eu comme résultat l'apparition de plusieurs "théologies régionales". (...) Nous avons dans l'islam un "pluralisme des théologies" qui nie toute théologie avec un grand " $T$ " $»^{21}$.

Pour E. Karić, l'islam est un, mais les cultures musulmanes qui en découlent sont évolutives, plurielles et irréductibles les unes aux autres. Dès le début des années 1990, il entend donc rouvrir les portes de l'ijtihad (effort d'interprétation), et affiche son hostilité envers le « fondamentalisme extrémiste » qui « ignore la limite entre la source de la foi et la traduction historique de cette source ", "donne des attributs divins à ce qui n'est 
qu'une interprétation humaine passée » et, plus concrètement, ramène l'islam, religion universelle, « à la religion de deux villes [La Mecque et Médine], la lie au sol, la réduit aux

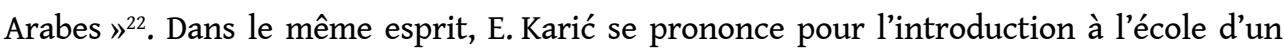
enseignement comparé des religions. En effet, il estime d'une part qu'un enseignement religieux par confession ne ferait que renforcer les «traits polémiques et de ce fait exclusifs » des grandes religions et, d'autre part, que le vrai lieu d'un enseignement religieux par confession n'est pas l'école publique, mais la mosquée ou l'église, car « la foi est avant tout un sentiment intime et profond, un sentiment personnel qui ne peut s'exprimer en dehors des limites, des ambiances, des espaces et des temps qui lui sont propres $»^{23}$.

Car, pour E. Karić, la foi est individuelle, mais elle n'est vivante que si elle s'inscrit dans une tradition et une culture communes. Cette insistance sur «l'islam comme foi et comme culture, comme système religieux et culturel des adeptes de l'islam en BosnieHerzégovine ${ }^{24}$ se reflète dans ses prises de position au cours du conflit bosniaque. Ainsi, contrairement à $\mathrm{F}$. Karčić, il n'hésite pas à attribuer à la guerre une dimension religieuse : il compare le combat des Musulmans bosniaques à celui du Prophète contre les infidèles à Badr ${ }^{25}$, affirme que par leur lutte, « les Bochniaques ont illuminé le visage de l'Umma »", et considère même que « les livres pieux, à commencer par le Coran, parlent du djihad comme de l'ensemble des activités qui contribuent à une expression digne de la foi islamique, à la préservation des biens, de l'honneur, de la vie, de la descendance.(...) Si les musulmans ont besoin d'un État pour protéger toutes ces valeurs, alors la création de cet État représente - d'un point de vue religieux - le djihad par excellence $»^{27}$. Toutefois, E. Karić ne cesse jamais d'affirmer que les Musulmans bosniaques ont deux patries, "l'européenne - leur terre natale, leur pays - et la spirituelle, islamique et orientale ${ }^{28}$. A ceux tentés par un "anti-européanisme agressif », il rappelle même que "l'Europe est notre patrie au sens large. Par l'origine, par la langue et par de nombreux segments de notre culture, nous sommes Européens. L'identité européenne des Bochniaques ne contredit pas leur identité musulmane $»^{29}$.

En tant que ministre de l'Éducation et de la Culture, E. Karić s'emploie à renforcer l'identité nationale musulmane, en organisant la publication de nouveaux manuels scolaires, en confiant la formalisation de la langue bosniaque à une commission de linguistes, en encourageant les activités de l'association culturelle musulmane «Preporod " ( Renaissance »). Cet activisme lui vaut parfois les critiques des partis «citoyens», quand il cautionne des manuels scolaires mettant côte à côte la thèse darwinienne de l'évolution des espèces et celle de la création divine du monde, ou quand il interdit la diffusion sur les ondes de musiques produites en Serbie ou en Croatie. Mais E. Karić rejette le multiculturalisme dont ces partis se réclament, «modèle hybride et artificiel qui signifie n'appartenir à aucune culture particulière ", et lui oppose une "multiculture bosniaque [qui] est le produit naturel des cultures traditionnelles de la Bosnie $»^{30}$, une «multiculturalité et multiconfessionalité véritables, (...) créées dans les échanges de la vie réelle, et non dans le but d'être montrées dans le monde comme une curiosité de musée » ${ }^{31}$.

Toutefois, si E. Karić se gausse parfois des «safaris multiculturalistes» de certains Occidentaux ${ }^{32}$, c'est aux missionnaires wahhabites qu'il réserve ses critiques les plus sévères. Il n'a de cesse, en effet, de dénoncer la façon dont ces missionnaires et leurs émules locaux insistent sur un formalisme stérile, et nient la culture de l'islam propre aux Musulmans bosniaques. Dans un texte essentiel intitulé « Notre identité bochniaque et notre 
identité musulmane», E. Karić écrit ainsi que "l'identité musulmane et l'islam des Bochniaques sont attaqués de toutes parts, mais avant tout de la part de musulmans locaux néophytes et agressifs, qui travaillent en collaboration avec des humanitaires aux intentions douteuses. Ils attaquent l'islam des Bochniaques justement là où il contribue le plus à l'affirmation de notre identité nationale et de notre matrice spirituelle ».

À cette "réduction de l'identité musulmane bosniaque à une foi grossière et stérile ", il oppose «la manière bosniaque de vivre l'islam comme foi, comme culture, comme civilisation, comme inspiration, comme identification spirituelle, (...) l'affirmation tolérante de toutes les manières traditionnelles et - pourquoi ne pas le dire bochniaques, de vivre l'islam en Bosnie ». Pour E. Karić, en effet, "de même que les Arabes ont leurs manières traditionnelles de vivre l'universalité de l'islam, nous avons les nôtres. Du reste, aucune nation musulmane, si elle est une nation, ne peut l'être sans ces spécificités qui ont été préservées pendant des siècles, en même temps qu'était soigneusement défendue l'universalité de l'islam $»^{33}$.

Si l'hostilité envers les représentants des courants wahhabites est une constante chez E. Karić, l'évolution de ses rapports avec les dirigeants du SDA et de l'Islamska Zajednica est plus inattendue. Dans un premier temps, en effet, sa définition de l'islam comme culture commune l'incite à participer à leurs côtés à la réaffirmation et à la réislamisation de l'identité nationale musulmane. Mais, peu à peu, elle l'amène aussi à dénoncer l'artificialité et la vulgarité d'un certain kitsch nationaliste, et à s'opposer à l'instrumentalisation politique de l'islam par le SDA.

Dès 1992, E. Karić associe sa définition de «l'islam comme foi et comme culture » à une acceptation du "principe de l'Etat laïc et de la séparation de la religion et de l'Etat ». D'après lui, ce principe est non seulement nécessaire à la coexistence des différentes communautés bosniaques, mais aux Musulmans eux-mêmes : " En effet, par ce biais est garanti le fait que l'islam est leur trésor partagé, en tant que religion, que culture et que tradition. Ainsi est assurée également la tolérance entre Musulmans, l'islam ne pouvant pas devenir la propriété de certains d'entre eux $\|^{34}$. C'est ce raisonnement qu'il développe trois ans plus tard, dans un texte où sa rupture avec le SDA apparait déjà en filigrane : « Il est très important que les Musulmans bosniaques aient accepté depuis longtemps déjà le principe d'une pratique, d'une expression et d'une manifestation de l'islam dans une société laïque et un État laïc. Ce principe, dans le contexte européen et à l'époque actuelle, sert les Musulmans bosniaques car il leur assure une expression de l'islam sans diktat idéologique et sans décret politico-idéologique sur ce qu'est le "vrai islam". L'islam est en Bosnie le trésor commun de tous les Bochniaques, ce précieux trésor dont ils tirent depuis des siècles leurs multiples inspirations religieuses, culturelles, artistiques, littéraires, urbaines, architecturales. Dans une telle conception (...), l'islam ne peut devenir la propriété ou l'exclusivité de personne, ni l'objet d'adaptations pragmatiques aux impératifs politiques du jour. Car les Bochniaques doivent se protéger contre euxmêmes, et contre les différentes formes d'ostracisme religieux, traditionnel, politique ou culturel. ॥ $^{35}$

De l'affirmation de la spécificité de l'islam bosniaque à la promotion de son pluralisme interne, la démarche de E. Karić reste finalement cohérente. Et c'est justement parce qu'il définit l'islam comme culture commune qu'il refuse de le voir réduit à une idéologie politique discriminante. 


\section{Adnan Jahić : I'islam comme idéologie politique discriminante}

Contrairement à F. Karčić et E. Karić, Adnan Jahić n'a pas de formation religieuse, bien qu'il soit issu d'une famille de notables ayant compté plusieurs oulémas dans ses rangs. Né en 1967 à Tuzla, il fait des études de philosophie et de journalisme à Sarajevo, au cours desquelles il soutient un mémoire sur «L'histoire des relations entre religion et philosophie, des temps anciens à Abu Nasr al-Farabi». En 1995, il publie également un ouvrage réhabilitant les formations musulmanes qui ont collaboré avec l'occupant pendant la Seconde Guerre mondiale, et dans lesquelles certains membres de sa famille semblent avoir joué un rôle important ${ }^{36}$.

Plus que par ses écrits philosophiques ou historiques, cependant, A. Jahić se fait connaître par ses activités éditoriales et politiques. À Tuzla, il est l'un des principaux collaborateurs du journal «Zmaj od Bosne » («Le dragon de la Bosnie » ${ }^{37}$ ), organe officieux du SDA local, et le rédacteur en chef du mensuel « Hikmet » ("Sagesse $\left.»^{38}\right)$, lancé par le nouveau mufti en 1993. Alors que «Hikmet» traite avant tout de sujets religieux, «Zmaj od Bosne» se distingue par ses attaques virulentes contre la mairie de Tuzla, tenue par les partis "citoyens ", et se fait même épingler par Tadeusz Mazowiecki, rapporteur pour l'exYougoslavie de la Commission des droits de l'homme de l'ONU, pour ses menaces proférées à rencontre des Serbes de la ville. Cela n'empêche pas A. Jahić de connaitre une ascension politique fulgurante : membre de la direction régionale du SDA à partir de 1994, il est élu à l'Assemblée de Bosnie-Herzégovine en septembre 1996, où il prend la présidence du groupe parlementaire SDA. Il doit démissionner de ce poste un an plus tard ${ }^{39}$, mais devient alors le porte-parole officiel du SDA.

La formation intellectuelle de A. Jahić se reflète dans son intérêt pour les rapports entre islam et philosophie. Il dénonce entre autres le «tournant cartésien par lequel le sujet individuel a reçu un primat méthodologique, puis éthique, axiologique et tous azimuts ", permettant ainsi l'apparition d' "un pluralisme philosophique au sens d'une diversité idéologique de buts et de fins ", et conduisant peu à peu " au matérialisme, au scientisme, à l'existentialisme et aux autres formes de pensée philosophique du monde moderne ». Aux divers courants de la philosophie occidentale moderne, il oppose donc une philosophie islamique qui, «par principe, ne peut être qu'une, et dont le thème central a été et reste Dieu et Sa Révélation, c'est-à-dire le divin et l'humain à la lumière de la Révélation». D'après lui, "cette forme de monolithisme ne doit en aucun cas être considérée comme une imperfection, mais comme une qualité et un signe de cohérence dans l'intention de départ $»^{40}$.

De même, A. Jahić oppose les conceptions occidentale et islamique de la démocratie. Pour la première, «les droits de l'homme et les libertés constituent la plus haute valeur de la collectivité. Là se situe la faiblesse fondamentale de la société occidentale : l'État et la société n'entretiennent pas une relation active, il n'y a pas de progression sur le plan spirituel et éthique. Le bien comme contenu s'épuise dans le politique comme forme ». La démocratie islamique, au contraire, renvoie au principe de tevhid (unicité de Dieu) et insiste sur "la perspective éthique de la démocratie»: «L'islam ne s'intéresse pas prioritairement à la démocratie formelle (bien qu'il ne s'y oppose en rien), mais à ses principes et ses valeurs éthiques positives qui vont contribuer à la réalisation de l'idée islamique au sein de la collectivité ». Pour A. Jahić, « il n'y aura jamais de place au sein de 
la pensée politique islamique pour la dite démocratie libérale de type occidental, qui ne se soucie pas du bien général de sa propre société, de son état spirituel et éthique $»^{41}$.

Contrairement à F. Karčić et E. Karić, A. Jahić conçoit donc les rapports entre Islam et Occident en termes d'opposition structurelle. Il affirme du reste que le monde occidental a pour but "l'anéantissement total du monde musulman » ${ }^{42}$, et appelle ce dernier à se débarrasser « du laïcisme, du sécularisme et du nihilisme occidentaux, du positivisme et du matérialisme existentialiste en philosophie et dans les sciences, de l'hédonisme et de l'utilitarisme dans le domaine de l'éthique et de la morale $»^{43}$. Il admet certes qu'en tant que Musulmans bosniaques, «nous appartenons à l'Occident sur le plan géographique, et en partie sur celui de la civilisation ». Mais c'est pour rappeler aussitôt que « nous ne lui appartenons en aucun cas culturellement et spirituellement ", et dénoncer l'influence occidentale en Bosnie-Herzégovine, sous la forme de la promiscuité sexuelle et de l'hédonisme, mais aussi « de la multiculture, des droits de l'homme et de la tolérance $»^{44}$. À ses yeux, le conflit bosniaque est donc aussi «l'affrontement final entre les valeurs nationales et culturelles autochtones des Bochniaques et celles, étrangères, importées de l'Occident, qui nous ont été imposées pendant de longues années comme étant les nôtres $»^{45}$.

Cette attitude de A. Jahić envers l'Occident influence inévitablement ses réflexions sur les rapports entre islam et identité nationale d'une part, islam et système politique d'autre part. Il dénonce en effet la pénétration des concepts occidentaux de nationalité et de laïcité dans le monde musulman, et leur oppose «l'unité politique de l'Umma et l'ordre social islamique $»^{46}$. Toutefois, dans un cas comme dans l'autre, A. Jahić se heurte vite à des réalités incontournables, et ses réflexions deviennent alors plus hésitantes. Ainsi, il appelle dans certains textes à renforcer l'unité de l'Umma contre les «particularismes de nature politico-étatique, nationale, civilisationnelle, linguistique, socio-culturelle et idéologique $»^{47}$. Ailleurs, il affirme au contraire que "les Bochniaques et les autres musulmans ont leur propre culture fondée sur l'islam enrichi par différentes traditions nationales $»^{48}$.

Au-delà de ces contradictions, sa réflexion la plus élaborée sur la question nationale reste sans doute un texte intitulé "Islam et nationalité à la lumière des circonstances actuelles dans le monde musulman ${ }^{49}$. Dans ce texte paru en 1995, A. Jahić réaffirme la prééminence de l' Umma comme idéal sur la nation comme simple réalité. Toutefois, il estime aussi nécessaire de mieux prendre en compte cette réalité et de la réconcilier avec l'islam. Ce que rejette A. Jahić, c'est donc avant tout la définition laïque de la nation, et en particulier les tentatives de minimiser le rôle de l'islam ou de valoriser le passé pré-islamique dans l'identité des nations musulmanes. Mais il dénonce aussi l'instrumentalisation nationale de l'islam, sa réduction à un substrat culturel. Pour A. Jahić, il faut au contraire restaurer l'islam dans son autonomie et sa transcendance pour qu'apparaisse enfin la vraie complémentarité entre islam et nationalité : «La nationalité a besoin de l'islam qui la complète et l'oriente sémantiquement, lui donne sa raison d'être ${ }^{50}$. Cependant, même la religiosité n'existe pas sans un support séculier, sans relais solide et puissant, à savoir ce sentiment national, ce sens inné de sa propre appartenance. (...) C'est pourquoi l'islam et la nationalité sont d'une certaine façon complémentaires. Il s'agit là d'une complémentarité de méthode, de fonction. Il ne s'agit pas d'une complémentarité de contenu. L'islam est, dans son contenu, parachevé. Dans son rapport avec le national, il peut ennoblir, embellir celui-ci, mais ne peut rien recevoir de lui. Cependant, la 
nationalité lui est nécessaire comme le peintre a besoin de la toile sur laquelle il va peindre son œuvre.»

Ayant posé le principe d'une complémentarité entre islam et nationalité, en même temps que celui de leur hiérarchisation, A. Jahić peut alors envisager « la lutte pour l'islam et contre le nationalisme hypertrophié » comme un processus graduel, dans lequel la priorité revient à la lutte contre la sécularisation, et relier ainsi la question des rapports entre islam et identité à celle des rapports entre islam et système politique. Selon A. Jahić, en effet, « l'harmonisation de l'islam et de la nationalité (...) ouvre la voie à une société islamique plus heureuse, sans laquelle il ne peut être question d'un État islamique véritable et réalisé de façon conséquente ${ }^{51}$.

41 À première vue, les positions de A. Jahić sur les rapports entre islam et système politique sont plus tranchées, puisqu'il oppose à la démocratie occidentale, formaliste et permissive, une démocratie islamique fondée sur des "valeurs éthiques positives ", et renvoyant aux principes de Califat (représentation de Dieu sur Terre), de shura (concertation) et de ijma (consensus ${ }^{52}$ ). Toutefois, A. Jahićpeine à définir ces valeurs et ces principes, et reconnaît lui-même la nécessité de "se déplacer de l'idéal de la théorie politique vers la réalité de ce qui est réalisable et possible $»^{53}$. Dans ce cadre, il estime qu' ' il faut renforcer les processus démocratiques dans le monde musulman, car (...) la démocratie est, dans les conditions actuelles, la voie la plus directe vers un pouvoir islamique $~^{54}$. Au-delà de cette considération tactique, il affirme qu'«il n'est possible d'établir un pouvoir islamique, c'est-à-dire un État fondé sur les normes et les règlements chariatiques, qu'à partir d'une société islamique saine et libre, c'est-à-dire une population majoritairement musulmane qui soutient consciemment une telle forme de pouvoir». Enfin, dans la mesure où « un pouvoir islamique sans soutien dans les masses populaires ne peut être légitime ", il considère que celui-ci doit se soumettre régulièrement au verdict des urnes, et que, "s'il perd les élections, la forme du pouvoir doit être réorganisée en fonction des préférences du vainqueur $\rrbracket^{55}$.

42 À aucun moment, A. Jahić n'oppose donc explicitement la Loi ou la volonté divine à la souveraineté populaire, ou ne reconnaît à la première une prééminence sur la seconde. Dès lors, ce ne sont pas tant les formes institutionnelles de la démocratie occidentale qu'il rejette, que son caractère laïc et séculier. Et, de fait, c'est autour du problème de la laïcité et du sécularisme que tournent la plupart de ses écrits. Ainsi, A. Jahić se fait lui aussi le chantre de l'ijtihad, mais en insistant sur les limites dans lesquelles il doit se situer: « nous ne pouvons pas concevoir l'ijtihad en dehors de son contexte islamique, ni penser qu'il soit possible de l'interpréter dans une perspective laïque ${ }^{56}$. De même, il dénonce la façon dont «l'islam, avec l'adoption [dans le monde musulman] des projets occidentaux de sécularisation radicale de la société et de l'État, a commencé à être évincé de tous les domaines de la vie politique et sociale ", la sécularisation étant peu à peu "passée du champ étatico-politique au champ culturel et éducatif ", et " la sécularisation spirituelle [étant] beaucoup plus dangereuse que la politique ${ }^{57}$. Puis, s'appuyant sur les propos du Reis-ul-Ulema Mustafa Cerić, il distingue deux sortes de sécularisme pour préciser ses positions à ce sujet: "Nous sommes contre le sécularisme métaphysique, qui nous éloignerait en tant que nation de notre foi, l'islam; nous sommes pour le sécularisme politique, qui est normal, et qui implique que les institutions et les organes de la dite religion ne vont pas se mêler des affaires de l'État et de nature politique. Par conséquent, nous sommes pour un État laïc au sens politique traditionnel, et nous sommes contre un État laïc au sens politique contemporain du terme. Nous sommes pour un État séparé de 
la religion dans sa forme, nous sommes contre un État qui serait aussi séparé de la religion dans son contenu. Et voilà pourquoi nous ne voulons pas une société laïque, nous ne voulons pas que les Bochniaques soient des laïcs (...). Nous voulons que l'islam soit notre impulsion morale, culturelle et intellectuelle, car nous ne pensons pas que cela puisse être la culture et la civilisation occidentales, dont nous connaissons les buts, ainsi que ceux de leurs promoteurs [locaux]. Voilà pourquoi il faut savoir que l'islam est une question collective, et non individuelle, une affaire de consensus le plus large possible, et non d'une quelconque volonté subjective $»^{58}$.

Finalement, A. Jahić est donc lui aussi conduit à s'interroger sur la définition de l'islam. De toute évidence, il rejette celle de l'islam comme foi individuelle: à l'éthique individualisée et intériorisée de F. Karčić, il oppose une morale collective et publique. Mais il rejette aussi la définition de l'islam comme culture commune, dénonçant cette partie de l'intelligentsia musulmane «qui est consciente de la place que l'islam occupe dans la constitution nationale de son peuple, mais lui donne avant tout une signification culturelle et traditionnelle, et très peu de signification réelle dans la vie [quotidienne] ${ }^{59}$. Pour A. Jahic, en effet, « celui qui croit possible d'être en contact avec l'islam de manière sporadique et superficielle, d'appliquer certains de ses préceptes et d'en négliger d'autres, doit être conscient de son inconséquence, et même d'une certaine hypocrisie. Il y a des éléments sans l'application desquels il n'y a pas d'islam, et par conséquent pas de musulman, et celui qui se déclare musulman, mais évite par exemple la mosquée ou le jeûne, ne peut pas être musulman $»^{60}$. Alors que dans la définition proposée par E. Karić, l'islam a pour vocation de rassembler la communauté musulmane, il a au contraire pour A. Jahić une fonction de différenciation au sein de cette même communauté.

Or, à partir du moment où l'islam ou, plus précisément, le «vrai islam » devient un critère de différenciation au sein de la communauté musulmane, A. Jahić n'a d'autre choix que de confier sa mise en œuvre au pouvoir politique, et les "valeurs éthiques positives » dont il parle ne sont donc finalement rien d'autre qu'une idéologie d'État officieuse. Le processus de différenciation mené sur cette base conduit inévitablement à des discriminations sociales et politiques de fait au sein de la communauté musulmane, et la distinction établie entre séparation de l'État et de la religion dans la forme d'une part, dans le contenu d'autre part, permet la reconstitution implicite d'un État-parti au sein de cadres institutionnels démocratiques. Comme le souligne A.Jahić lui-même, «la préservation et le renforcement de l'islam dépendra en premier lieu de son degré de présence dans les programmes scolaires d'État, dans les mass-media, dans la littérature populaire et dans les autres sphères d'activité sociale. L'État n'a pas besoin d'être formellement islamique pour pouvoir encourager de telles formes d'islamisation subtile de la société $\aleph^{61}$.

Cette volonté de A. Jahić d'ériger l'islam en idéologie politique discriminante apparaît de manière plus crue dans un texte qui fit grand bruit à Tuzla lors de sa parution en septembre 1993. Dans ce texte intitulé «Un robuste État musulman »62, A. Jahić ne fait pas que briser un tabou en se prononçant pour la création d'un État musulman dans "l'espace sur lequel restera après la guerre notre armée de Bosnie-Herzégovine » ${ }^{63}$. Il affirme aussi que "l'islam, par sa nature même, ne connaît pas de division entre le religieux et le social. Plus encore, l'islam n'est pas une "religion", mais une idéologie politico-religieuse, une Weltanschauung complète. Les principes islamiques ne restent jamais à la surface des consciences individuelles et des sentiments religieux privés. 
L'islam originel cherche à englober la société dans laquelle il existe, et donc les structures politico-étatiques elles-mêmes ».

Dès lors, selon A. Jahić toujours, «l'État musulman aura une idéologie musulmane fondée sur l'islam, les principes juridico-religieux et éthico-sociaux islamiques, mais aussi les éléments de provenance occidentalo-européenne qui ne rentrent pas en contradiction avec les précédents ", cette idéologie devant être " érigée en système politico-juridique complet du futur État musulman, des symboles étatiques et nationaux aux institutions scolaires, sociales et économiques en passant par la politique gouvernementale nationale ». Cela implique qu' « aucun principe de l'idéologie musulmane ne sera imposé à quelqu'un par la force, selon le principe "La ikrahe fi-d-din" ["Pas de contrainte en religion"], mais que son esprit sera systématiquement promu et instillé dans la société ». Concrètement, « une pleine égalité des droits sera garantie par la loi à tous les citoyens, mais le niveau de réussite sociale de chaque individu dépendra non seulement de sa propre activité économique, mais aussi de son degré d'acceptation et d'application conscientes des principes et de l'esprit de l'idéologie musulmane ».

Enfin, pour que le mimétisme avec l'ancien État-parti soit complet, A. Jahićprécise que "dans la gestion de l'État, il faudra maintenir pendant les premières décennies une politique centralisatrice, insister strictement sur l'application et le respect des lois adoptées, de sorte que l'État puisse le plus tôt possible tenir sur ses jambes et commencer à prescrire les contenus de l'idéologie islamique. Ce n'est qu'ensuite que pourra suivre une large décentralisation et démocratisation de la société ».

\section{Conclusion : vers un post-islamisme bosniaque?}

Les écrits de F. Karčić, E. Karić et A. Jahić attestent que la communauté musulmane de Bosnie-Herzégovine est, elle aussi, impliquée dans les multiples débats qui portent sur la définition de l'islam et de ses rapports avec l'État moderne, les catégories nationales ou la civilisation occidentale, et qui concernent l'ensemble du monde musulman. Dès lors, la simple présentation de ces écrits suffit pour réfuter toute description de l'islam bosniaque en termes d'« islam européen » homogène et sui generis, dont la modernité et la tolérance intrinsèques s'opposeraient à l'intolérance et au conservatisme supposés de l'« islam non-européen ». En Bosnie-Herzégovine comme ailleurs, l'islam est une réalité plurielle et mouvante, insaisissable en dehors des clivages qui la traversent et des acteurs qui l'animent.

Cela ne signifie pas, bien sûr, que l'islam bosniaque n'ait pas ses spécificités, ou qu'il ne s'inscrive pas dans un cadre particulier. Ainsi, le contexte historique de sortie du communisme transparaît quand $F$. Karčić voit dans l'avènement du multipartisme une occasion de dépolitiser les institutions religieuses, ou quand, au contraire, A. Jahić entend placer l'islam au cœur d'un nouveau modèle d'État-parti. De même, la situation géographique des Musulmans bosniaques, placés aux marges européennes de l'Umma et entourés de populations chrétiennes, se reflète dans les interrogations des trois auteurs sur la double identité musulmane et européenne des Musulmans bosniaques ou sur les possibles implications politiques de l'islam en Bosnie-Herzégovine. Enfin, la confrontation à un État non-musulman à partir de 1878, la marginalisation des institutions religieuses dans l'après-guerre et le rapide déclin de la religiosité des Musulmans bosniaques au cours des dernières décennies expliquent leur insistance sur les questions de laïcité de l'État et de sécularisation de la société. 
50 Mais ces spécificités bien réelles, et dont la traduction la plus surprenante est sans doute le fait qu'une population musulmane fortement sécularisée ait porté à sa tête les représentants d'un courant panislamiste minoritaire ${ }^{64}$, ne font souvent que donner une coloration ou une visibilité particulières à des évolutions qui se retrouvent elles aussi, plus ou moins, dans l'ensemble du monde musulman. De ce point de vue, il ne faudrait pas voir dans l'ordre de présentation des auteurs retenus ici, ou même dans leurs trajectoires individuelles, un résumé des évolutions récentes de l'islam bosniaque. Certes, ce n'est pas un hasard si E. Karić se retrouve à la fin de la guerre dans l'opposition au SDA, alors que A. Jahić en est devenu une des figures de proue. Mais les renouvellements du parti au pouvoir ne reflètent que partiellement les transformations de la communauté musulmane bosniaque, et ne suffisent en aucun cas pour comprendre les processus et les débats qui traversent l'islam bosniaque.

51 De toute évidence, il y a eu de la part du courant fondateur du SDA une volonté d'ériger l'islam en idéologie politique discriminante, de réislamiser " par en haut» la population musulmane bosniaque et de renforcer ses liens avec le reste de l'Umma. Les écrits de A. Jahić peuvent donc être considérés comme l'expression d'un projet politique partagé par les autres représentants du courant panislamiste bosniaque, bien que resté la plupart du temps implicite. Mais ce projet s'est vite heurté à un certain nombre de contraintes extérieures, ainsi qu'à ses propres contradictions : la tentative des dirigeants du SDA de placer l'islam au cœur de l'identité musulmane bosniaque a par exemple débouché sur une véritable "nationalisation » de l'islam en Bosnie-Herzégovine et leur volonté de promouvoir le sentiment d'appartenance à l'Umma ne les a pas empêché de faire appel aux grandes puissances occidentales, puis d'accepter leur protectorat de fait en BosnieHerzégovine.

Surtout, les résistances et les apories auxquelles s'est heurtée la tentative d'ériger l'islam en idéologie politique discriminante ont eu pour conséquence une redécouverte de l'islam comme culture commune et comme foi individuelle. Ainsi, dans les débats qui les ont opposés au SDA, les partis « citoyens » ont souvent mis en avant ces deux définitions de l'islam. De même, l'instrumentalisation des institutions religieuses ayant conduit à leur discrédit, certaines voix se sont faites entendre en leur sein, plaidant pour une séparation plus nette du religieux et du politique. Enfin, au fur et à mesure que l'islam était accepté par la population musulmane comme fondement de son identité nationale, de multiples acteurs s'en emparaient, le réinterprétaient et l'utilisaient pour contester l'hégémonie du SDA. D'une façon plus générale, le débat sur la nature de l'islam en Bosnie-Herzégovine reste passablement confus et informel, et son issue très incertaine. Mais les argumentations en présence et les évolutions en cours ne sont pas sans rappeler celles que d'autres chercheurs remarquent dans le monde musulman, et qu'ils regroupent sous le terme générique de « post-islamisme $»^{65}$. 


\section{NOTES}

1. Voir Tarek MITRI, "La Bosnie-Herzégovine et la solidarité du monde arabe et islamique ", Maghreb-Machrek, n 139, janvier 1993, pp. 123-136.

2. Xavier BougAReL, «L'islam et la guerre en Bosnie-Herzégovine : l'impossible débat ? ", L'Autre Europe, $\mathrm{n}^{\circ}$ 36-37, hiver 1998/1999, pp. 106-116.

3. Xavier BOUGAREL, " Un courant panislamiste en Bosnie-Herzégovine », in Gilles KEPEL, éd., Exils et royaumes. Les appartenances au monde arabo-musulman aujourd'hui, Paris, Presses de la FNSP, 1994, pp. 275-299.

4. Voir Fikret KARČıć, Šeriatski sudovi u Jugoslaviji 1918-1941[Les tribunaux chariatiques en Yougoslavie 1918-1941], Sarajevo, Islamska Zajednica, 1986 ; Fikret KARČIć, Društveno-pravni aspekti islamskog reformizma [Aspects socio-juridiques du réformisme islamique], Sarajevo, Islamski Teološki Fakultet, 1990.

5. Fikret KARČıć, «Islamska Zajednica i reforma jugoslovenčkog političkog sistema » [La Communauté islamique et la réforme du système politique yougoslave], Glasnik Rijaseta IZ-e, vol. LII, $n^{\circ} 1$, janvier-février 1990, pp. 7-13.

6. Voir Xavier BOUGAREL, « Un courant panislamiste en Bosnie-Herzégovine », op. cit.

7. Fikret KARČŕć, Šerialski sudovi...,op. cit., p. 155.

8. Intervention au colloque «Le droit dans l'islam » organisé par la mosquée de Zagreb en avril 1991, citée dans Muslimanski Glas, Ire année, $\mathrm{n}^{\circ}$ 2, 3 mai 1991, p. 14.

9. Fikret KARČIć, «O “islamskoj republici” u BiH » [Á propos de la "république islamique” en Bosnie-Herzégovine], Preporod, XXI ${ }^{\mathrm{e}}$ année, $\mathrm{n}^{\circ} 3$, $1^{\mathrm{er}}$ février 1990, p. 3.

10. Fikret KARčIć, Društveno-pravni aspekti..., op. cit., p. 195.

11. Fikret KARČIć, « Razumijevanje islamskog vjerozakona (šeriata) u savremenom muslimanskom svijetu » [La perception de la loi islaraique (charia) dans le monde musulman contemporain], in N. ČANČAR, Enes KARIć, dirs., Islamski fundamentalizam. Šta je to? [Le fondamentalisme islamique, qu'est-ce que c'est ?], Sarajevo, Biblioteka "Preporoda" i "Islamske misli", 1990, pp. 37-43.

12. Fikret KARČıć, «Značenje i iskazivanje islama u svjetovnoj državi» [Signification et expression de 1'islam dans l'État laic), dans Enes KARIĆ, dir., Suvremena ideologijska tumačenja Kur'ana i islama [Les interprétations idéologiques contemporaines du Coran et de l'islam], Zagreb, Kulturni rad-nik, 1990, pp. 29-36.

13. Les oulémas divisent généralement le monde en deux « maisons », la « maison de l'islam » ( dar al-islam) qui rassemble tous les États musulmans, et la « maison de la guerre » (dar al-harb) qui recouvre les États n'étant pas de religion musulmane. Certains leur ajoutent une troisième «maison», la «maison du contrat» (dar al-ahd), qui recouvre les États non-musulmans permettant á leurs minorités musulmanes de pratiquer leur religion

14. Fikret KARČrć, «Islamic Revival in the Balkans ", Islamic Studies, vol. XXXVI, n²-3, étéautomne 1997, pp. 565-581.

15. Fikret KARČÍ́, «Distorted Images of Islam : the Case of Former Yugoslavia », Intellectual Discourse, vol. III, n² 2, 1995, pp. 139-152.

16. Fikret KARČIĆ, "Ubijanje naroda u sjeni "sudara civilizacija" " [Le massacre d'un peuple à l'ombre du "choc des civilisations"], Ljiljan, IV e année, n 111, $1^{\mathrm{er}}$ mars 1995, pp. 32-33.

17. Voir Xavier BOUGAREL, « Un courant panislamiste en Bosnie-Herzégovine », op. cit.

18. Enes KARIĆ, Hermeneutika Kur'ana [Herméneutique du Coran], Zagreb, Biblioteka Filo-zofska istraživanja, 1990. 
19. Enes KARIć, dir., Suvremena ideologijska tumačenja..., op.cit.; Enes KARIć, dir., Kur'an u savremenom dobu [Le Coran à l'époque contemporaine], Sarajevo, Svjetlost, 1991.

20. Kur'an sa phjevodom na bosanski jezik [Le Coran avec traduction en langue bosniaque], Sarajevo, Bosanska knjiga, 1995.

21. Enes KARIĆ , Hermeneutika Kur'ana, op.cit., p. 247. Un propos similaire se retrouve dans le commentaire d'E. Karić à sa propre traduction du Coran : "le Coran est donné une fois pour toutes en tant que Parole divine, mais la compréhension et l'interprétation du Coran ne sont pas scellées pour toujours. Les musulmans d'aujourd'hui doivent savoir que chaque nouvelle interprétation du Coran est en même temps interprétation active du monde et recherche d'une place digne en son sein. Chaque nouvelle chute de pluie fertile provient de nuages différemment disposés dans le même ciel » (Enes KARIć, « Kur'anski univerzum (pogovor prijevodu) » [L'univers coranique (postface à la traduction)], Kur'an sa prijevodom...], op. cit., p. 1269.

22. Enes KARIĆ, «Fundamentalizam Prokrustove postelje » [Fondamentalisme : le lit de Procuste], dans N. ČANČAR, Enes KARIĆ, dir., Islamski fundamentalizam. žta je to ?, op. cit., pp. 89-93.

23. Enes KARIć, «Dvosjekli mač vjeronauke u školi» [Le sabre à double tranchant de l'enseignement religieux à l'école], Muslimanski Glas, $\mathrm{II}^{\mathrm{e}}$ année, $\mathrm{n}^{\circ}$ 10, 28 juin 1991, p. 15. Cette position personnelle d'E. Karić s'oppose à celle des instances dirigeantes de l'Islamska Zajednica, qui se prononcent en faveur d'un enseignement religieux par confession, et parviennent à imposer cette formule à E. Karić en 1994.

24. Enes KARIĆ, «Značenje i iskazivanje islama u budućoj Bosni i Hercegovini » [Signification et expression de l'islam dans la future Bosnie-Herzégovine], in Collectif, Kongres BosanskoMuslimanskih intelektualaca (22. decembar 1992), Sarajevo, Bosnagraf, 1993, pp. 97-100. Le titre de ce texte de E. Karić fait de toute évidence allusion au texte publié deux ans auparavant par F. Karčić. 25. Enes KARIć, « Bosna je bošnjački Bedr » [La Bosnie est le Badr bochniaque], Ljiljan, III ${ }^{\mathrm{e}}$ année, $\mathrm{n}$ - 58, 23 février 1994, p. 31.

26. Enes KARIĆ, «Bošnjaci su Ummetu osvjetlali obraz » [Les Bochniaques ont sauvé la face de l'Umma], Ljiljan, III ${ }^{\mathrm{e}}$ année, $\mathrm{n}^{\circ}$ 61, 16 mars 1994, p. 31.

27. Enes KARIć, «Agresija na Bosnu i Hercegovinu i pitanje džihada », in Collectif, Duhovna snaga odbrane, Sarajevo, Vojna biblioteka, n 5, 1994, pp. 73-77. En linguiste et philologue averti, E. Karić revient toutefois sur la polysémie du terme " djihad », avant de constater que, d'un point de vue religieux, «ce que font les combattants de l'armée de la République de Bosnie-Herzégovine est bien un djihad du plus haut niveau », mais que «certains combattants le font par patriotisme, d'autres par patriotisme et motivation religieuse, d'autres encore par courage et héroïsme, d'autres enfin pour protéger leur famille et leurs biens ». Dans ce contexte, E. Karić considère $q^{\prime}$ '« il ne semble pas indiqué d'effacer toutes ces motivations qui forment la mosaïque de la résistance héroïque des Bochniaques, surtout pas en imposant quoi que ce soit qui pourrait être mal accueilli par les combattants, ou du moins par certains d'entre eux ».

28. Enes KARIĆ, «Značenje i ískazivanje íslama u budućoj Bosni i Hercegovini », op. cit.

29. Enes KARIĆ, « Naše bosanstvo i naše evropejstvo » [Notre identité bosniaque et notre identité européenne], Ljiljan, $\mathrm{VI}^{\mathrm{e}}$ année, $\mathrm{n}^{\circ}$ 263, 28 janvier 1998, p. 20.

30. Enes KARIĆ, «Suze, stepe i pustinje » [Larmes, steppes et déserts], Ljiljan, III ${ }^{\mathrm{e}}$ année, $\mathrm{n}^{\circ} 100$, 14 décembre 1994, p. 53.

31. Enes KARIĆ, «Značenje i iskazivanje islama u budućoj Bosni i Hercegovini », op. cit.

32. Enes KARIĆ, « Suze, stepe i pustinje », op. cit.

33. Enes KARIĆ, «Naše bošnjaštvo i naše muslimanstvo " [Notre identité bochniaque et notre identité musulmane], Ljiljan, $\mathrm{VI}^{\mathrm{e}}$ année, $\mathrm{n}^{\circ}$ 264, 4 février 1998, pp. 20-22.

34. Enes KARIĆ, «Značenje i iskazivanje islama u budućoj Bosni i Hercegovini », op. cit.

35. Enes KARIĆ, «Islam u suvremenoj Bosni » [L'islam dans la Bosnie contemporaine], in Bosna sjete i zaborava [La Bosnie du chagrin et de l'oubli], Zagreb, Durieux, 1997, pp. 88-95. 
36. Adnan JAHIĆ, Muslimanske formacije tuzlanskog kraja u drugom svjetskom ratu [Les formations musulmanes de la région de Tuzla pendant la Seconde Guerre mondiale], Tuzla, Bosnoljublje, 1995.

37. Ce titre est une allusion à Husein-kapetan Gradaščević, un notable musulman de Gradačac dans la région de Tuzla, qui se révolta en 1831 contre les réformes administratives et militaires imposées par le pouvoir central ottoman et prit alors le nom de guerre de Zmaj od Bosne. La révolte de Husein-kapetan Gradaščević est aujourd'hui présentée par les historiens musulmans bosniaques comme une des premières manifestations de l'éveil national des Musulmans bosniaques.

38. Dans l'entre-deux-guerres, Hikmet était à Tuzla l'organe des oulémas traditionnalistes opposés au réformisme modernisateur du Reis-ul-Ulema Džemaludin Čaušević. Voir Fikret KARČrć, Društvenopravni aspekti islamskog reformizma, op. cit.

39. En septembre 1997, les députés des trois partis nationalistes (SDA musulman, SDS serbe et HDZ croate) à l'Assemblée de Bosnie-Herzégovine élisent à la présidence de la Commission pour les droits de l'homme le député Velibor Ostojić, haut responsable du SDS soupçonné d'avoir pris une part active dans le «nettoyage ethnique » de la ville de Foča (Bosnie orientale) en 1992. Face aux protestations des partis « citoyens » et des médias indépendants, le SDA fait machine arrière, expliquant alors le vote de ses députés par un «malentendu », et Adnan Jahić doit démissionner de la présidence du groupe parlementaire SDA.

40. Adnan JAHIĆ, «Baqir As-Sadr i naša filozofija » [Baqir As-Sadr et notre philosophie], Hikmet, vol. VIII, n 8/92, août 1995, pp. 360-363. Plus concrètement, A. Jahić reconnaît bien un certain " enfermement [de la pensée musulmane médiévale] dans des cadres méthodologiques surannés (...), ce qui a empêché tout renouvellement et tout enrichissement intellectuel de la discipline philosophique dans le monde musulman». Mais aux "tentatives inarticulées d'adaptation superficielle et de réconciliation de fond avec certains thèmes philosophiques venus de l'Occident ", il préfère une "dynamisation de la démarche [philosophique islamique], de façon méthodique et rationnelle, dans laquelle certaines expériences occidentales seraient tout à fait bienvenues » (Ibid.)

41. Adnan JAHIĆ, «Zavičajnost demokratije $u$ islamskom političkom mišljenju » [L'enracinement de la démocratie dans la pensée politique islamique], Hikmet, vol. IX, n 9-12/105-108, novembre 1996, pp. 247-254.

42. Adnan JAHIĆ, «Bošnjaci i Zapad - principi budućih odnosa » [Les Bochniaques et l'Occident les principes de relations futures], Hikmet, vol. VIII, n 4/88, avril 1995, pp. 148-150.

43. Adnan JAHIĆ, «Neke opservacije o političkim perspektivama islamskog svijeta » [Quelques observations sur les perspectives politiques du monde musulman], Hikmet, vol. VIII, n 6/90, juin 1995, pp. 248-253.

44. Adnan JAHIĆ, « Bošnjaci i Zapad - principi budućih odnosa », op. cit.

45. Adnan JAHIĆ, «Znamo a nećemo ?! " [Nous savons mais nous ne voulons pas ?!], Hikmet, vol. VIII, n² 2/86, février 1995, pp. 52-53.

46. Adnan JAHIĆ, « Neke opservacije o političkim perspektivama islamskog svijeta », op. cit.

47. Adnan JAHIĆ, « Neke opservacije o političkim perspektivama islamskog svijeta », op. cit.

48. Adnan JAHIĆ, « Bošnjaci i Zapad - principi budućih odnosa », op. cit.

49. Il s'agit là d'une contribution à un colloque international organisé en octobre 1995 par la mosquée de Zagreb et intitulé «Le monde musulman aujourd'hui ».

50. En français dans le texte.

51. Adnan JAHIĆ, «Islam i nacionalitet u svjetlu suvremenih prilika u islamskom svijetu » [Islam et nationalité à la lumière des circonstances actuelles dans le monde musulman], Hikmet, vol. VIII, $\mathrm{n}^{\circ}$ 10-11/94-95, novembre 1995, pp. 448-452.

52. Adnan JAHIĆ, « Zavičajnost demokratije u islamskom političkom mišljenju », op. cit. 
53. Adnan JAHIĆ, « Neke opservacije o političkim perspektivama islamskog svijeta », op. cit.

54. Adnan JAHIĆ, « Neke opservacije o političkim perspektivama islamskog svijeta », op. cit.

55. Adnan JAHIĆ, «Zavičajnost demokratije u islamskom političkom mišljenju », op. cit.

56. Adnan JAHIĆ, « Zavičajnost demokratije u islamskom političkom mišljenju », op. cit.

57. Adnan JAHIĆ, «Islam i nacionalitet u svjetlu suvremenih prilika u islamskom svijetu », op. cit.

58. Adnan JAHIĆ, «Islam - pitanje zajednice » [L'islam, une question de communauté], Hikmet, vol. VIII, n 9/93, septembre 1995, pp. 390-391.

59. Adnan JAHIĆ, «Znamo a nećemo ?! », op. cit.

60. Adnan JAHIĆ, « Znamo a nećemo ?! », op. cit.

61. Adnan JAHIĆ, «Islam i nacionalitet u svjetlu suvremenih prilika u islamskom svijetu », op. cit.

62. Adnan JAHIĆ, « Krijeposna muslimanska država » [Un robuste État musulman], Zmaj od Bosne, 27 septembre 1993, reproduit dans Fatmir Alispahić, Krv boje benzina [Un sang couleur d'essence], Tuzla, Radio Kameleon, 1996, pp. 248-251.

63. Adnan Jahić affirme qu'en cela, il ne fait qu'exprimer les choix du Président du SDA Alija Izetbegović et du Reis-ul-Ulema Mustafa Cerić : «ce dernier m'a clairement confirmé lors d'une conversation privée que le rêve éternel de Alija Izetbegović, Jeune Musulman, était et est encore la création d'un État musulman en Bosnie-Herzégovine ; voilà que ce rêve se réalise, et cela ne le dérange pas vraiment $»$.

64. Pour une explication de ce paradoxe, voir Xavier BOUGAREL, «Un courant panislamiste en Bosnie-Herzégovine ", op. cit.

65. Sur le "post-islamisme », voir en particulier Olivier RoY, "Le post-islamisme ", Revue des mondes musulmans et de la Méditerranée, nº 85-86, 1999, pp. 11-30.

\section{RÉSUMÉS}

Depuis la fin du XIX ${ }^{\mathrm{e}}$ siècle, les débats religieux qui traversent la communauté musulmane bosniaque s'articulent autour de trois points : 1) les rapports entre islam et identité nationale des Musulmans bosniaques ; 2) les rapports entre islam et système politique en Bosnie-Herzégovine ; 3) la place de la Bosnie-Herzégovine dans les rapports entre monde musulman et monde occidental. La constitution du Parti de l'action démocratique (SDA) en 1990 et l'indépendance de la Bosnie-Herzégovine en 1992 n'ont fait qu'exacerber ces débats, mais le contexte de la guerre les a souvent rendus sous-jacents et difficilement perceptibles de l'extérieur. Dans ce contexte, la présentation des écrits de trois intellectuels musulmans Bosniaques (Fikret Karčić, Enes Karić, Adnan Jahić), et des définitions de l'islam qu'ils y défendent (foi individuelle, culture commune, idéologie politique discriminante), permet de mieux comprendre les clivages autour desquels s'articulent les recompositions identitaires et politiques récentes de la communauté musulmane bosniaque.

Since the end of the $19^{\text {th }}$ century, the religious debates which divide the Bosnian Muslim community focus on three main points: 1) the relationship between Islam and the national identity of Bosnian Muslims; 2) the relationship between Islam and the political system in BosniaHerzegovina; 3) the place of Bosnia-Herzegovina in the relationship between the Muslim world and the Western world. The creation of the Party of Democratic Action (SDA) in 1990 and the independance of Bosnia-Herzegovina in 1992 have only exacerbated these debates, but the war 
context has often kept them underlying and difficult to perceive from the outside. Against this background, the presentation of the writings of three Bosnian Muslim intellectuals (Fikret Karčić, Enes Karić, Adnan Jahić), and of their respective definitions of Islam (individual faith, collective culture, differentiating political ideology), leads to a better understanding of the clivages around which the political life and identity of the Bosnian Muslim community have been recently reshaped.

Desde fines del s. XIX, los debates religiosos que atraviesa la comunidad musulmana bosnia se articulan alrededor de tres puntos : 1 . Las relaciones entre el Islam y la identidad nacional de los Musulmanes bosnios; 2. las relaciones entre el Islam y el sistema político en BosniaHerzegovina ; 3. el lugar de Bosnia-Herzegovina en las relaciones entre el mundo musulmán y el mundo occidental. La constitución del Partido de Acción Democrática (SDA) en 1990 y la independencia de Bosnia-Herzegovina en 1992 exacerbaron estos debates, pero el contexto de la guerra los volvió subyacentes y difícilmente perceptibles desde el exterior. En este contexto, la presentación de los escritos de tres intelectuales musulmanes bosnios (Fikret Karčić, Enes Karić, Adnan Jahić), y las definiciones del Islam que ellos defienden (fe individual, cultura común, ideología política discriminante), permiten comprender mejor los clivajes en torno de los cuales se articulan las recomposiciones identitarias y políticas recientes de la comunidad musulmana bosnia.

\section{AUTEUR}

\section{XAVIER BOUGAREL}

Centre d'Études du domaine turc - CNRS 